\title{
Policosanol Attenuates Cholesterol Synthesis via AMPK Activation in Hypercholesterolemic Rats
}

\author{
Da-Eun Nam, Jeong-Moon Yun, ${ }^{2}$ Dakyung Kim, ${ }^{2}$ and Ok-Kyung $\mathrm{Kim}^{3}$ \\ ${ }^{1}$ Carter Immunology Center, University of Virginia School of Medicine, Charlottesville, Virginia, USA. \\ ${ }^{2}$ Research Institute of Clinical Nutrition, Kyung Hee University, Seoul, Korea. \\ ${ }^{3}$ Division of Food and Nutrition and Human Ecology Research Institute, Chonnam National University, Gwangju, Korea.
}

\begin{abstract}
This study was carried out to investigate the effects of policosanol on high-fat and high-cholesterol dietinduced hypercholesterolemic rats to provide strong evidence in support of its hypocholesterolemic effect. The hypercholesterolemic rats showed elevations in liver weight, total triglycerides, total cholesterol, and low-density lipoprotein (LDL) cholesterol in serum; however, policosanol supplementation reduced these markers significantly. In addition, we found that policosanol supplementation stimulated an increase in fecal cholesterol and bile acid contents and deactivated 3-hydroxy-3methylglutaryl-CoA (HMG-CoA) reductase by AMP-activated protein kinase (AMPK) phosphorylation during high-fat and high-cholesterol-containing diet-induced development of hypercholesterolemia. Policosanol supplementation decreased ApoB levels and increased LDL-receptor expression, but it did not affect the hepatic ACAT2 level in livers from hypercholesterolemic rats. Moreover, supplementation with policosanol significantly decreased aortic wall thickness and levels of P-selectin and soluble vascular cell adhesion molecule (sVCAM-1) in serum. In conclusion, we suggest that policosanol supplementation induces antihypercholesterolemia by inhibiting cholesterol biosynthesis, LDL cholesterol uptake, and cholesterol excretion.
\end{abstract}

KEYWORDS: • AMPK $\bullet H M G-C o A$ reductase $\bullet$ hypercholesterolemia $\bullet$ LDL cholesterol $\bullet$ policosanol

\section{INTRODUCTION}

$\mathbf{C}_{\mathrm{P}}^{\mathrm{H}}$ HOLESTEROL IS REQUIRED to maintain membranes and produce steroid hormones, vitamin $\mathrm{D}$, and bile acid. However, abnormally elevated cholesterol levels in the blood, particularly low-density lipoprotein (LDL) cholesterol, known as hypercholesterolemia, are regarded as a major risk factor for the development of cardiovascular diseases. ${ }^{1}$ Thus, it is an increasing medical problem and the principal cause of mortality all over the world. ${ }^{2}$ Control of plasma cholesterol levels essentially involves metabolism of both intracellular (endogenous) and extracellular (exogenous) cholesterol. Therefore, it is desirable to avoid ingestion and suppress $d e$ novo synthesis of excessive cholesterol, and to promote its excretion for the maintenance of normal body function. ${ }^{3,4}$

Intracellular cholesterol levels are tightly controlled by cholesterol secretion into blood and uptake from plasma LDL cholesterol or activation of $\beta$-hydroxy $\beta$-methylglutaryl-CoA (3-hydroxy-3-methylglutaryl-CoA [HMG-CoA]) reductase. Cholesterol is biosynthesized by HMG-CoA reductase, expression of which is regulated by the sterol regulatory

Manuscript received 16 May 2019; Revision accepted 23 August 2019.

Address correspondence to: Ok-Kyung Kim, PhD, Division of Food and Nutrition and Human Ecology Research Institute, Chonnam National University, 77 Yongbong-Dong, Buk-Gu, Gwangju 61186, Republic of Korea, E-mail: 20woskxm@chonnam.ac.kr element-binding protein 2 , and the biosynthesis is deactivated by AMP-activated protein kinase (AMPK) activation. When cholesterol levels are high in the cells, AMPK phosphorylation deactivates phosphorylation of HMG-CoA reductase. $^{5-7}$ Therefore, HMG-CoA reductase inhibitors, known as statins, such as atorvastatin, lovastatin, and simvastatin, have been effectively used for lowering LDL cholesterol. However, long-term consumption of these drugs may cause side effects including muscle pain and damage, liver damage, diabetes, and neurological side effects. ${ }^{8,9}$ Therefore, there is increasing interest in the potential of medicinal plants that exhibit hypocholesterolemic effect. ${ }^{10-12}$

Policosanol is a long-chain (22-34 carbons) and highmolecular weight aliphatic alcohol obtained from various natural foods, including sugarcane, rice bran, fruits, and nuts. ${ }^{13}$ Policosanol has been reported to have hypocholesterolemic, antiaging, and anti-inflammatory effects, and has been used in functional foods. ${ }^{14,15}$ Previous studies have shown that policosanol can inhibit HMG-CoA reductase activity by AMPK phosphorylation, which inhibits cholesterol synthesis in the in vitro model, but the underlying mechanisms remain poorly understood in in vivo model. ${ }^{14}$ Thus, we evaluated the antihypercholesterolemic effects of policosanol on cholesterol biosynthetic enzymes and intermediates in the in vivo model using high-fat and highcholesterol diet-induced rats. 


\section{MATERIALS AND METHODS}

\section{Measurement of fatty alcohol composition in policosanol}

We obtained the policosanol from Oz Nature Korea Co., Ltd. Measurement of fatty alcohol composition in policosanol was performed by gas chromatography (GC) using an Agilent 7890A (USA, KHSI-A-000) and Agilent 7890B (USA, KHSI-A-039) with FID detector and Agilent J\&W DB-1 column $(30 \mathrm{~m} \times 0.32 \mathrm{~mm} \times 0.25 \mu \mathrm{m})$. The injector temperature was $320^{\circ} \mathrm{C}$ with a $2: 1$ split and $1 \mu \mathrm{L}$. The initial oven temperature was $230^{\circ} \mathrm{C}$, then increased to $320^{\circ} \mathrm{C}$ for $15 \mathrm{~min}$. The carrier gas was $\mathrm{N}_{2}$, at $20 \mathrm{~mL} / \mathrm{min}$. Peaks were identified using standards for tetracosanol, hexacosanol, heptacosanol, octacosanol, and triacontanol obtained from Sigma-Aldrich (Oakville, Canada). Nonacosanol, dotriacontanol, and tetratriacontanol were identified using sugarcane (Saccharum officinarum L.) wax.

\section{Treatment and induction of hypercholesterolemia in rats}

Male Sprague Dawley rats (age, 8 weeks; weight, 330$350 \mathrm{~g}$ ) were purchased from SaeRon Bio (Uiwang, Korea) and housed under controlled room temperature $\left(25^{\circ} \mathrm{C} \pm 2^{\circ} \mathrm{C}\right)$ with $12 \mathrm{~h}$ light and dark cycles. They had ad libitum access to food and purified water. After 1 week of adaptive feeding, all the rats were randomly divided into five groups of eight rats per group: control, HC (high-fat and highcholesterol diet control), policosanol $10 \mathrm{mg} / \mathrm{kg}$ body weight (b.w.) (high-fat and high-cholesterol diet with policosanol $10 \mathrm{mg} / \mathrm{kg}$ b.w.), policosanol $20 \mathrm{mg} / \mathrm{kg}$ b.w. (high-fat and high-cholesterol diet with policosanol $20 \mathrm{mg} / \mathrm{kg}$ b.w.), and simvastatin $15 \mathrm{mg} / \mathrm{kg}$ b.w. (positive control; high-fat and high-cholesterol diet with simvastatin $15 \mathrm{mg} / \mathrm{kg}$ b.w.). The normal control group was given a standard pellet diet (AIN 93G) and the hypercholesterolemia models were developed using a high-fat and high-cholesterol diet D12336 (Research Diets, Inc., NJ, USA) for 12 weeks. During the high-cholesterol diet administration, policosanol and simvastatin were orally administered once a day. The experimental protocol was approved by the Animal Care and Use Review Committee of Kyung Hee University (KHUASP[GC]-18-034).

\section{Measurement of lipid profiles, aspartate transaminase, and alanine transaminase in the serum}

At the end of the experiments, all rats were fasted for $12 \mathrm{~h}$ and anesthetized with isoflurane. Blood was collected from the ventricular artery and placed in the EDTA tube and used for platelet count testing. Blood was centrifuged at $14000 \mathrm{~g}$ for $10 \mathrm{~min}$, and the serum was separated and stored at $-80^{\circ} \mathrm{C}$ before blood analysis. Concentrations of total triglycerides (TGs), total cholesterol (TC), very LDL (VLDL)/LDL cholesterol, high-density lipoprotein (HDL) cholesterol, aspartate transaminase (AST), and alanine transaminase (ALT) in serum were determined by enzymelinked colorimetric methods using commercial kits (Biovision, CA, USA).

TC and bile acid concentration in feces from hypercholesterolemic rats

Metabolic cages are designed to provide a perfect separation of feces and urine through the funnel and separation cone. At first, metabolic cage food and water baskets are calibrated and filled with water and AIN 93G diet. Rats are individually housed in metabolic cages and checked daily for access to food and water. After $24 \mathrm{~h}$, feces from each rat was collected separately and was subjected to measure cholesterol and bile acid contents (Crystal Chem, IL, USA), determined by colorimetric methods using commercial kits.

HMG-CoA reductase activity and ApoB and ACAT levels in liver from hypercholesterolemic rats

HMG-CoA reductase activity of liver was measured using HMG-CoA reductase activity colorimetric assay kit (Abcam, Cambridge, MA, USA). Protein levels of ApoB and ACAT in liver were measured using commercial kits (MyBioSource, San Diego, CA, USA).

\section{Total RNA isolation and real-time polymerase chain reaction}

Total RNA was extracted from the rat livers using Qiagen RNeasy Mini kit, and cDNA was synthesized from purified total RNA using an iScript ${ }^{\mathrm{TM}}$ cDNA Synthesis Kit (Bio-Rad Laboratories, Hercules, CA, USA). Real-time polymerase chain reaction (PCR) was performed using a SYBR Green PCR Master Mix (Bio-Rad Laboratories). The cDNA was amplified using 40 cycles of denaturation $\left(95^{\circ} \mathrm{C}\right.$ for $\left.30 \mathrm{sec}\right)$, annealing $\left(55^{\circ} \mathrm{C}\right.$ for $\left.30 \mathrm{sec}\right)$, and extension $\left(72^{\circ} \mathrm{C}\right.$ for $\left.60 \mathrm{sec}\right)$ using the following primers: GAPDH forward primer $5^{\prime}$ ATG GAA ATC CCA TCA CCA TCT T- $3^{\prime}$, reverse primer 5'-CGC CCC ACT TGA TTT TGG-3'; HMG-CoA reductase forward primer $5^{\prime}$-CCT GCG TGT CCC TGG TCC TA- $3^{\prime}$, reverse primer $5^{\prime}$-CTT TGG GTT ACT GGG TTT GG-3'; LDL-receptor forward primer 5'-CAG CTC TGT GTG AAC CTG GA- $3^{\prime}$, reverse primer $5^{\prime}$-TTC TTC AGG TTG GGG ATC AG-3'. The 7500 System SDS software version 1.3.1 (Applied Biosystems) was used for data processing and relative quantitation.

\section{Western blotting}

Equal amounts of protein $(80 \mu \mathrm{g} / \mathrm{lane})$ from lysed rat livers were separated through sodium dodecyl sulfatepolyacrylamide gel electrophoresis and transferred to polyvinylidene difluoride membranes (Bio-Rad Laboratories). The membranes were incubated for $1 \mathrm{~h}$ in a blocking solution containing 5\% nonfat milk in Tris-buffered saline, and then incubated for $12 \mathrm{~h}$ at $4{ }^{\circ} \mathrm{C}$ with antibodies recognizing phospho-AMPK, LDL receptor, and $\beta$-actin (1:1000; Cell Signaling Technology, Inc.). The membranes were incubated with a secondary antibody (antirabbit IgG HRP-linked 
Table 1. Fatty Alcohol Profiling and Quantification of Standardized Policosanol

\begin{tabular}{lc}
\hline Content $(\mathrm{mg} / \mathrm{g})$ & \\
\hline Tetracosanol & $9.07 \pm 2.02$ \\
Hexacosanol & $81.54 \pm 15.49$ \\
Heptacosanol & $9.99 \pm 3.37$ \\
Octacosanol & $650.40 \pm 9.25$ \\
Nonacosanol & $14.72 \pm 1.59$ \\
Triacontanol & $146.42 \pm 4.33$ \\
Dotriacontanol & $55.80 \pm 4.58$ \\
Tetratriacontanol & $29.85 \pm 6.80$ \\
\hline
\end{tabular}

antibody, 1:5000, Cell Signaling Technology, Inc.) for $2 \mathrm{~h}$ at room temperature. The immunoreactive protein bands were detected through enhanced chemiluminescence (ECL), using ECL Western blotting detection reagents (Bio-Rad Laboratories).

\section{Measurement of P-selectin, soluble vascular cell} adhesion molecule 1 , and nitric oxide in the serum

The concentrations of P-selectin and soluble vascular cell adhesion molecule 1 (sVCAM-1) in the serum were measured using the ELISA Kit (Mybiosource, Inc., CA, USA) according to the manufacturer's protocol. The concentration of nitric oxide (NO) in the serum was measured using the NO ELISA Kit (ENZO Lifescience, PA, USA) according to the manufacturer's protocol.

\section{Measurement of aortic wall thickness}

The aorta of rats were fixed in $10 \%$ paraformaldehyde for histological studies, embedded in paraffin, and sectioned into $5 \mu \mathrm{m}$ slices. The sections were stained with hematoxylin and eosin and observed by light microscopy.

\section{Statistical analysis}

All results are expressed as mean \pm standard deviation and statistical analysis was performed by one-way ANOVA, using SPSS (SPSS PASW Statistic 23.0; SPSS, Inc., Chicago, IL, USA). Duncan's multiple range test was used to examine the difference among the groups. A $P$ value of $<.05$ was considered significant.

\section{RESULTS}

\section{Validation by measurement of fatty alcohol composition in policosanol}

We measured the fatty alcohol composition in policosanol by a GC method to assess compliance with standards and specifications (Table 1 and Fig. 1). This policosanol had high concentrations of octacosanol $(28: 0,650.40 \pm 9.25 \mathrm{mg} / \mathrm{g})$, triacontanol $(30: 0,146.42 \pm 4.33 \mathrm{mg} / \mathrm{g})$, and hexacosanol $(26: 0,81.54 \pm 15.49 \mathrm{mg} / \mathrm{g})$.

\section{Policosanol improved lipid profile in hypercholesterolemic rats}

Consuming a high-fat and high-cholesterol diet triggers dyslipidemia, as well as nonalcoholic fatty liver. ${ }^{16} \mathrm{We}$ found that HC (high-fat and high-cholesterol-containing diet control) fed rats had increased liver weight and TGs, TC, and LDL cholesterol levels in serum, but decreased HDL cholesterol level in serum compared with those in a normal diet control (Control), indicating normal development of a hypercholesterolemic rat model. Rats fed with a high-fat and high-cholesterol-containing diet supplemented with policosanol for 12 weeks had significantly reduced liver weight and TGs, TC, and LDL cholesterol levels in serum when compared with those in the $\mathrm{HC}$ rats. However, there was no

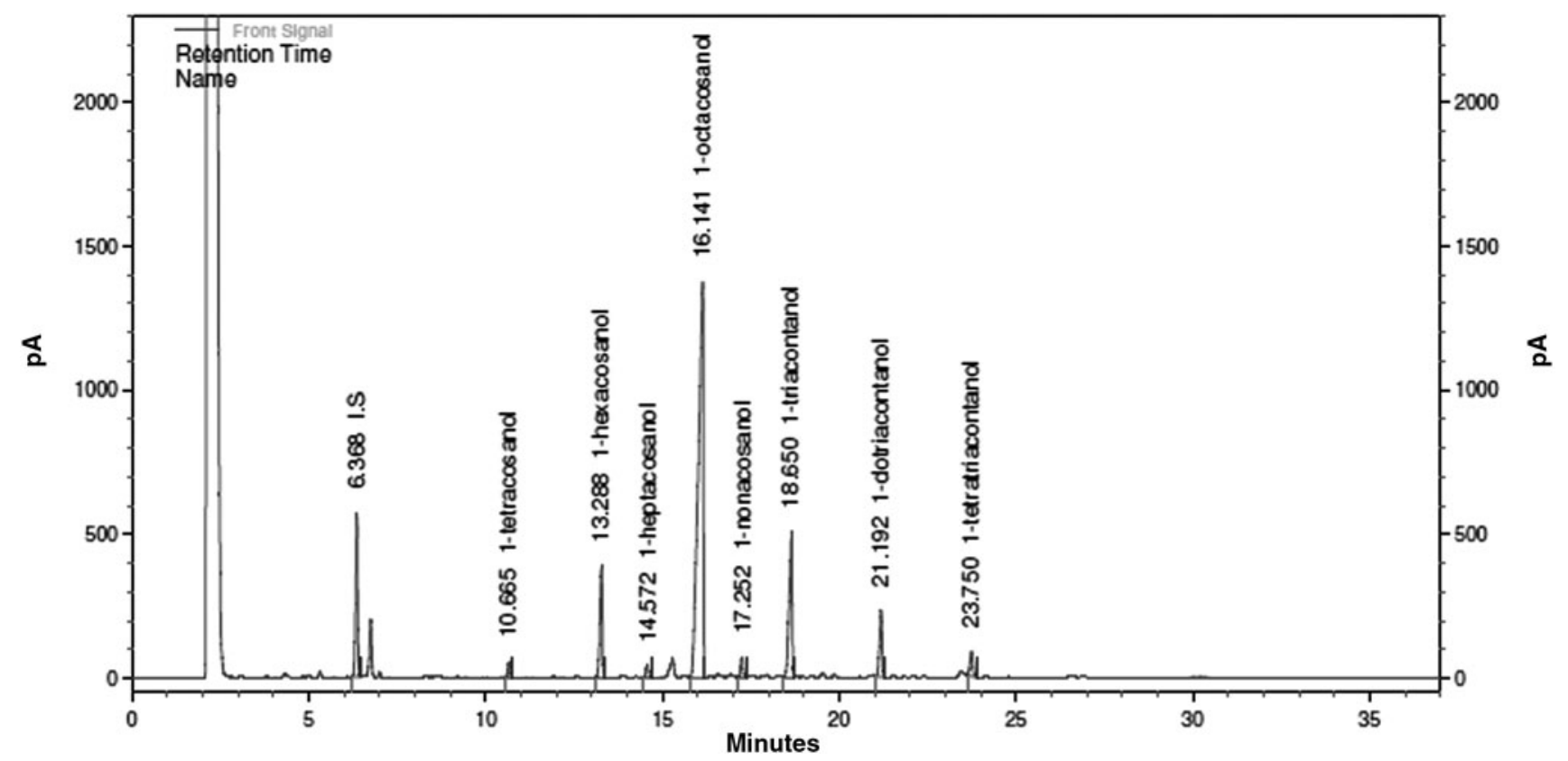

FIG. 1. Fatty alcohol profiling and quantification of standardized policosanol. pA, picoamperes. 
Table 2. Change in Liver Weight and Various Biochemical Parameters in Serum of Hypercholesterolemic Rats Fed with Diet Supplemented with Policosanol

\begin{tabular}{lccccc}
\hline & Control & HC & Policosanol(10 mg/kg) & Policosanol(20 mg/kg) & Simvastatin(15 mg/kg) \\
\hline Liver weight/b.w (\%) & $2.31 \pm 0.08^{\mathrm{c}}$ & $2.9 \pm 0.25^{\mathrm{a}}$ & $2.6 \pm 0.19^{\mathrm{b}}$ & $2.5 \pm 0.11^{\mathrm{b}}$ & $2.7 \pm 0.19^{\mathrm{b}}$ \\
Total triglyceride (mg/dL) & $78.4 \pm 14.25^{\mathrm{e}}$ & $183.6 \pm 22.43^{\mathrm{a}}$ & $144.7 \pm 11.73^{\mathrm{b}}$ & $120.1 \pm 13.13^{\mathrm{c}}$ & $98.6 \pm 9.81^{\mathrm{d}}$ \\
Total cholesterol (mg/dL) & $68.2 \pm 10.11^{\mathrm{e}}$ & $160.3 \pm 24.96^{\mathrm{a}}$ & $138.5 \pm 18.75^{\mathrm{b}}$ & $105.9 \pm 10.82^{\mathrm{c}}$ & $148.4 \pm 11.28^{\mathrm{a}}$ \\
LDL cholesterol (mg/dL) & $46.4 \pm 9.40^{\mathrm{c}}$ & $132.6 \pm 14.96^{\mathrm{a}}$ & $118.7 \pm 10.63^{\mathrm{ab}}$ & $94.5 \pm 11.28^{\mathrm{b}}$ & $55.3 \pm 13.81^{\mathrm{c}}$ \\
HDL cholesterol (mg/dL) & $32.4 \pm 4.45^{\mathrm{a}}$ & $20.1 \pm 5.27^{\mathrm{c}}$ & $24.5 \pm 4.86^{\mathrm{c}}$ & $23.1 \pm 5.34^{\mathrm{bc}}$ & $27.3 \pm 2.71^{\mathrm{b}}$ \\
AST (U/L) & $62.4 \pm 5.45^{\mathrm{c}}$ & $85.1 \pm 6.41^{\mathrm{a}}$ & $70.2 \pm 7.31^{\mathrm{b}}$ & $72.95 \pm 10.21^{\mathrm{b}}$ & $69.7 \pm 8.82^{\mathrm{bc}}$ \\
ALT (U/L) & $22.6 \pm 3.48^{\mathrm{c}}$ & $38.3 \pm 5.46^{\mathrm{a}}$ & $36.7 \pm 4.94^{\mathrm{a}}$ & $29.9 \pm 5.34^{\mathrm{b}}$ & $32.8 \pm 6.29^{\mathrm{ab}}$ \\
\hline
\end{tabular}

Values are presented as means \pm SD.

Different superscript letters show a significant difference at $P<.05$, as determined by Duncan's multiple range test.

Control, normal AIN93M diet control group; HC, high-fat and high-cholesterol diet control group; policosanol $10 \mathrm{mg} / \mathrm{kg}$, high-fat and high-cholesterol diet with

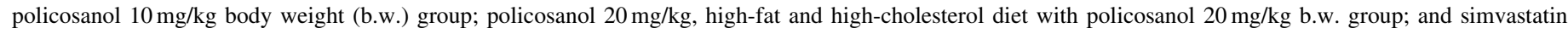
$15 \mathrm{mg} / \mathrm{kg}$, positive control high-fat and high-cholesterol diet with simvastatin $15 \mathrm{mg} / \mathrm{kg}$ b.w. group.

ALT, alanine transaminase; AST, aspartate transaminase; HDL, high-density lipoprotein; LDL, low-density lipoprotein; SD, standard deviation.

significant difference in HDL cholesterol levels between rats fed with policosanol supplemented diet and $\mathrm{HC}$ rats $(P<.05)$ (Table 2).

We investigated the level of AST and ALT in the serum to determine whether policosanol influenced liver damage or hepatotoxicity. Supplementation with $20 \mathrm{mg} / \mathrm{kg}$ policosanol significantly decreased AST and ALT levels compared with those in the HC group; however, their levels were higher than those in the control group $(P<.05)$ (Table 2). The ranges for all groups were within the normal range, which does not affect toxicity.

\section{Policosanol-induced excretion of cholesterol and bile acid in hypercholesterolemic rats}

We investigated the levels of TC and bile acid in feces of hypercholesterolemic rats to confirm whether policosanol influenced cholesterol excretion. Supplementation with $20 \mathrm{mg} / \mathrm{kg}$ policosanol significantly increased TC and bile acid levels compared with those in the control or HC groups
$(P<.05)$ (Fig. 2). This result indicated that supplementation with policosanol resulted in increased excretion of cholesterol by bile acid excretion, thus suppressing the increase in serum cholesterol levels.

\section{Policosanol affected the activation of HMG-CoA reductase but not mRNA expression in hypercholesterolemic rats}

To confirm the effects of policosanol on HMG-CoA reductase mRNA expression and activity, we measured HMGCoA reductase mRNA levels and activity in the liver of hypercholesterolemic rats. We found that there was no significant difference in mRNA levels of HMG-CoA reductase among $\mathrm{HC}$, policosanol, and simvastatin groups. However, policosanol and simvastatin groups showed a decrease in HMG-CoA reductase activity compared with that in the HC group $(P<.05)$ (Fig. 3). These data indicate that policosanol and simvastatin influence HMG-CoA reductase activation, but not mRNA expression.
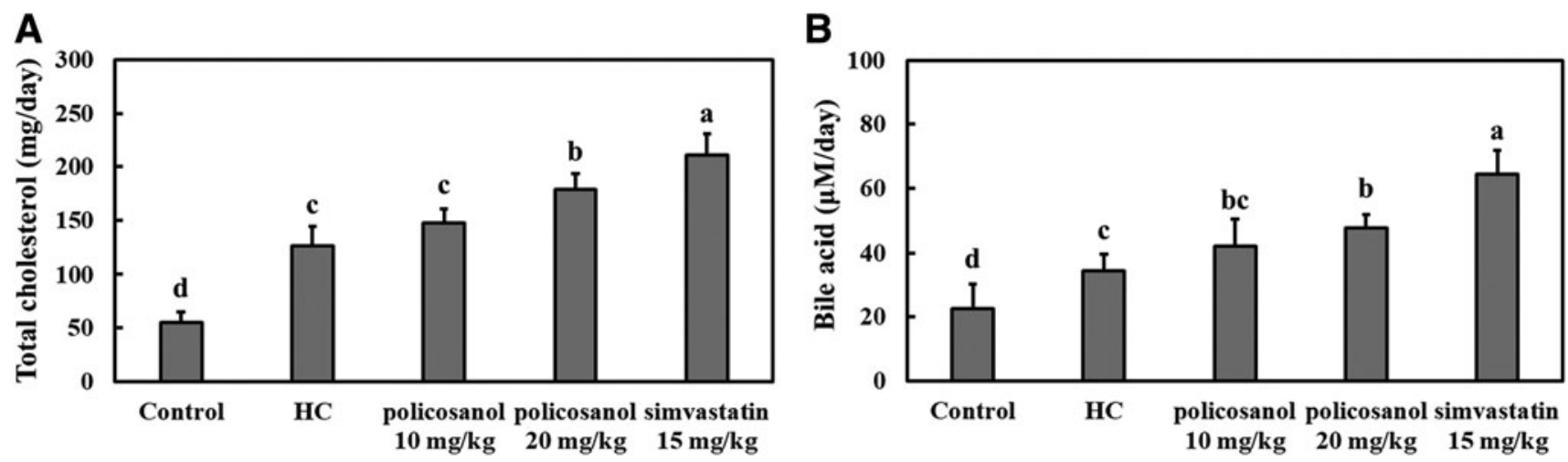

FIG. 2. Total cholesterol (A) and bile acid concentration (B) from feces of hypercholesterolemic rats supplemented with policosanol. Control, normal AIN93M diet control group; HC, high-fat and high-cholesterol diet control group; policosanol $10 \mathrm{mg} / \mathrm{kg}$, high-fat and high-cholesterol diet with policosanol $10 \mathrm{mg} / \mathrm{kg}$ body weight (b.w.) group; policosanol $20 \mathrm{mg} / \mathrm{kg}$, high-fat and high-cholesterol diet with policosanol $20 \mathrm{mg} / \mathrm{kg}$ b.w. group; and simvastatin $15 \mathrm{mg} / \mathrm{kg}$, positive control high-fat and high-cholesterol diet with simvastatin $15 \mathrm{mg} / \mathrm{kg} \mathrm{b.w}$. group. Values are presented as means \pm SD. Different letters show a significant difference at $P<.05$, as determined by Duncan's multiple range test. SD, standard deviation. 

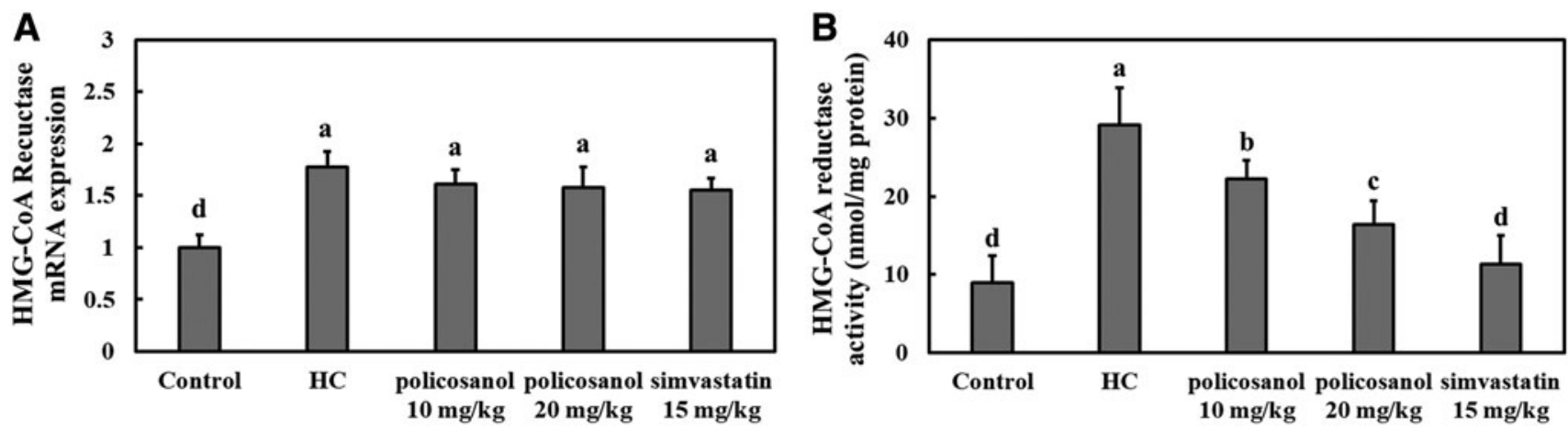

FIG. 3. Effects of policosanol supplementation on mRNA expression (A) and enzyme activity (B) of HMG-CoA reductase in the liver from hypercholesterolemic rats. Control, normal AIN93M diet control group; HC, high-fat and high-cholesterol diet control group; policosanol $10 \mathrm{mg} / \mathrm{kg}$, high-fat and high-cholesterol diet with policosanol $10 \mathrm{mg} / \mathrm{kg} \mathrm{b.w}$. group; policosanol $20 \mathrm{mg} / \mathrm{kg}$, high-fat and high-cholesterol diet with policosanol $20 \mathrm{mg} / \mathrm{kg}$ b.w. group; and simvastatin $15 \mathrm{mg} / \mathrm{kg}$, positive control high-fat and high-cholesterol diet with simvastatin $15 \mathrm{mg} / \mathrm{kg}$ b.w. group. Values are presented as means \pm SD. Different letters show a significant difference at $P<.05$ as determined by Duncan's multiple range test.

\section{Policosanol stimulated AMPK activation in hypercholesterolemic rats}

HMG-CoA reductase activation is inhibited by phosphorylation through AMPK activation. ${ }^{17}$ Thus, we measured AMPK phosphorylation in hypercholesterolemic rat livers. High-fat and high-cholesterol diet did not affect AMPK phosphorylation, but policosanol and simvastatin groups showed a significant increase in AMPK phosphorylation compared with that in control and $\mathrm{HC}$ groups $(P<.05)$ (Fig. 4). Therefore, we suggest that

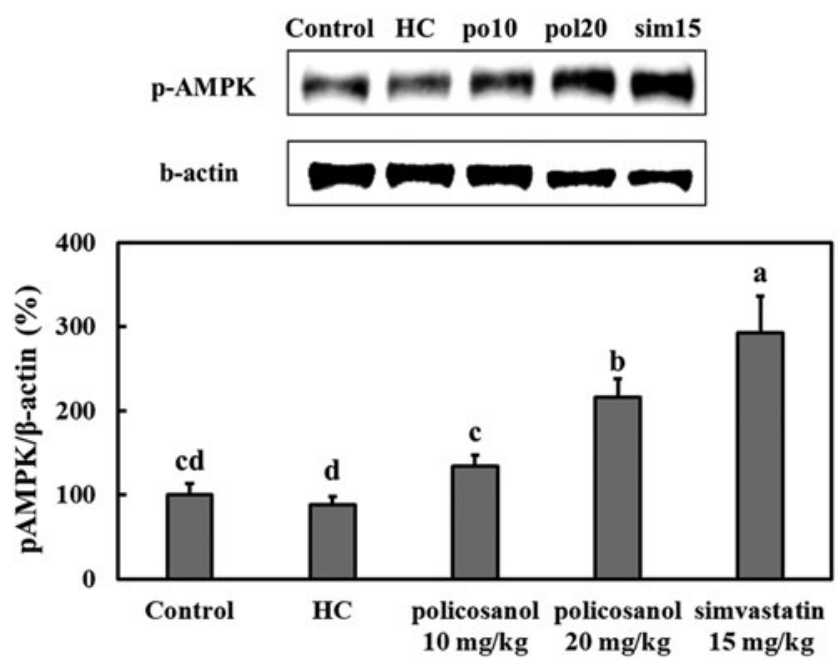

FIG. 4. Effects of policosanol supplementation on AMKP phosphorylation in hypercholesterolemic rat livers. Control, normal AIN93M diet control group; HC, high-fat and high-cholesterol diet control group; policosanol $10 \mathrm{mg} / \mathrm{kg}$, high-fat and high-cholesterol diet with policosanol $10 \mathrm{mg} / \mathrm{kg}$ b.w. group; policosanol $20 \mathrm{mg} / \mathrm{kg}$, high-fat and high-cholesterol diet with policosanol $20 \mathrm{mg} / \mathrm{kg}$ b.w. group; and simvastatin $15 \mathrm{mg} / \mathrm{kg}$, positive control high-fat and highcholesterol diet with simvastatin $15 \mathrm{mg} / \mathrm{kg}$ b.w. group. Values are presented as means \pm SD. Different letters show a significant difference at $P<.05$ as determined by Duncan's multiple range test. policosanol can inhibit HMG-CoA reductase activation by AMPK phosphorylation during high-fat and highcholesterol diet intake.

\section{Policosanol stimulated LDL receptor expression in hypercholesterolemic rats}

A high-fat and high-cholesterol diet resulted in a decrease in mRNA and protein expression of LDL receptor in the liver of hypercholesterolemic rats compared with normal rats. However, mRNA and protein levels of LDL receptor were considerably higher in the policosanol and simvastatin groups than in the HC group $(P<.05)$ (Fig. 5). These results suggest that not only simvastatin but also policosanol stimulates the uptake of LDL cholesterol into tissue, thus lowering cholesterol levels in the blood.

\section{Policosanol affected hepatic ApoB but not hepatic ACAT2 levels in hypercholesterolemic rats}

Levels of hepatic ApoB protein, which along with VLDL and LDL that play a role in triglyceride and cholesterol transport from the liver to the peripheral tissues, ${ }^{18}$ were increased by ingesting high-fat and high-cholesterol diet. However, $20 \mathrm{mg} / \mathrm{kg}$ policosanol and simvastatin groups showed a decrease in hepatic ApoB protein levels compared with those in $\mathrm{HC}$ groups $(P<.05)$ (Fig. 6A).

We measured the levels of hepatic cholesterol acyltransferase 2 (ACAT2), which produces cholesterol esters from cholesterol, and found no significant differences between its levels in policosanol and HC groups, whereas simvastatin induced a reduction in ACAT2 levels $(P<.05)$ (Fig. 6B). This suggests that policosanol does not affect esterification of cholesterol.

\section{Policosanol decreased atherosclerotic wall thickness}

To confirm the effects of policosanol on atherosclerotic wall thickness, we measured aortic wall thickness and levels of P-selectin, sVCAM-1, and NO in serum. Supplementation with policosanol significantly decreased aortic wall 
A

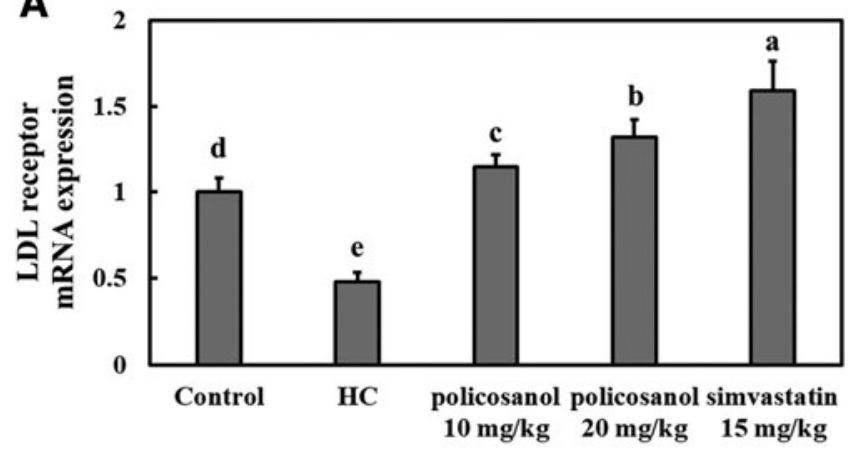

B

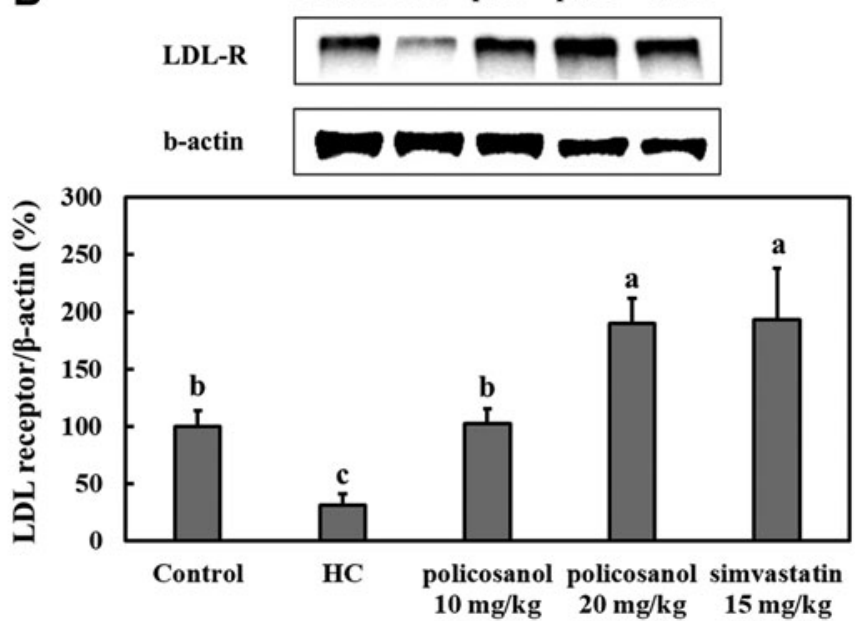

FIG. 5. Effects of policosanol supplementation on mRNA (A) and protein (B) expression of LDL receptor in hypercholesterolemic rat livers. Control, normal AIN93M diet control group; HC, high-fat and high-cholesterol diet control group; policosanol $10 \mathrm{mg} / \mathrm{kg}$, high-fat and highcholesterol diet with policosanol $10 \mathrm{mg} / \mathrm{kg}$ b.w. group; policosanol $20 \mathrm{mg} / \mathrm{kg}$, high-fat and high-cholesterol diet with policosanol $20 \mathrm{mg} / \mathrm{kg}$ b.w. group; and simvastatin $15 \mathrm{mg} / \mathrm{kg}$, positive control high-fat and high-cholesterol diet with simvastatin $15 \mathrm{mg} / \mathrm{kg}$ b.w. group. Values are presented as means \pm SD. Different letters show a significant difference at $P<.05$, as determined by Duncan's multiple range test. LDL, low-density lipoprotein

thickness compared with those in the $\mathrm{HC}$ groups $(P<.05)$ (Fig. 7A, B). In addition, the level of NO (Fig. 7C) in serum was increased, and levels of P-selectin (Fig. 7D) and sVCAM-1(Fig. 7E) in serum were decreased in groups supplemented with policosanol compared with those in the HC groups $(P<.05)$. This result suggests that supplementation with policosanol can suppress development of thrombosis and atherosclerosis.

\section{DISCUSSION}

Increased LDL cholesterol levels in the blood stimulate formation of plaque by oxidized LDL cholesterol-induced macrophage foam cells, which eventually lead to the development of atherosclerosis. It can be caused by a diet high in fat, lack of physical activity, obesity, type 2 diabetes, smoking, and aging. ${ }^{19}$ According to numerous reports, the con- tinuous ingestion of high-fat/high-cholesterol diets is a major environmental contributor for inducing hypercholesterolemia, not only in humans but also in rats. ${ }^{20,21}$ Thus, this study utilized a high-fat and high-cholesterol-containing diet in rats to investigate the effects of policosanol on diet-induced development of hypercholesterolemia. We observed a significant increase in blood cholesterol and triglyceride levels in rats fed with high-fat and high-cholesterol-containing diets, and found that policosanol suppressed it as expected. Therefore, we analyzed levels of cholesterol and bile acid in feces, and HMG-CoA reductase in the liver from rats to check whether reduction in cholesterol levels by policosanol is achieved by increased excretion or inhibition of biosynthesis.

Hepatic synthesis of bile acids is a major pathway for hepatic cholesterol catabolism for elimination of excess cholesterol, but most bile acids are reabsorbed in the ileum that inhibits bile acid synthesis and cholesterol catabolism.
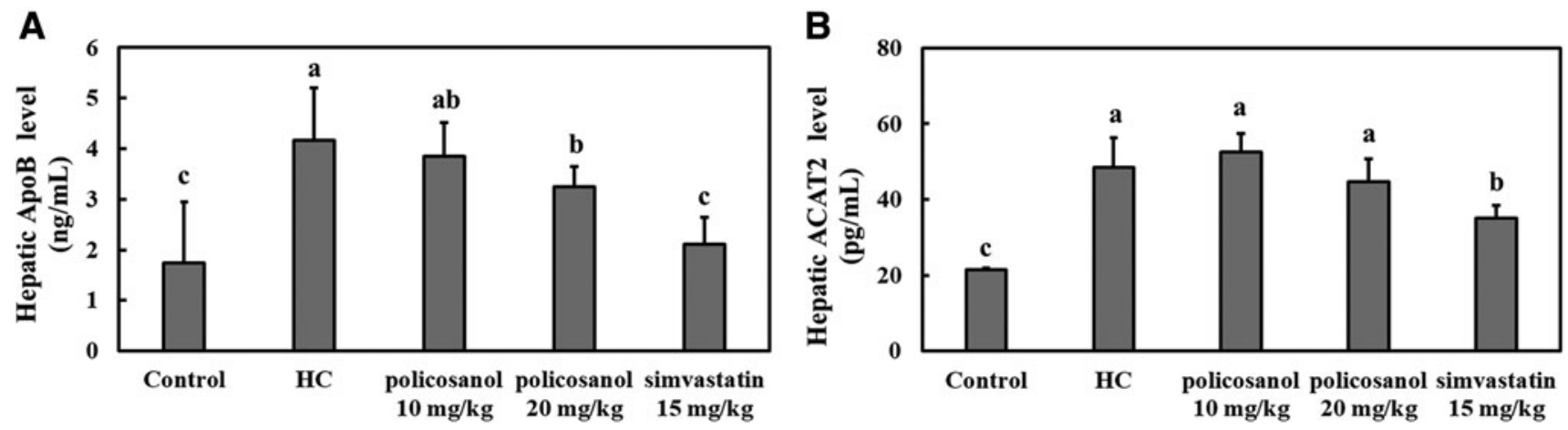

FIG. 6. Effects of policosanol supplementation on ApoB protein level (A) and ACAT protein level (B) in hypercholesterolemic rat livers. Control, normal AIN93M diet control group; HC, high-fat and high-cholesterol diet control group; policosanol $10 \mathrm{mg} / \mathrm{kg}$, high-fat and highcholesterol diet with policosanol $10 \mathrm{mg} / \mathrm{kg}$ b.w. group; policosanol $20 \mathrm{mg} / \mathrm{kg}$, high-fat and high-cholesterol diet with policosanol $20 \mathrm{mg} / \mathrm{kg}$ b.w. group; and simvastatin $15 \mathrm{mg} / \mathrm{kg}$, positive control high-fat and high-cholesterol diet with simvastatin $15 \mathrm{mg} / \mathrm{kg}$ b.w. group. Values are presented as means \pm SD. Different letters show a significant difference at $P<.05$, as determined by Duncan's multiple range test. 

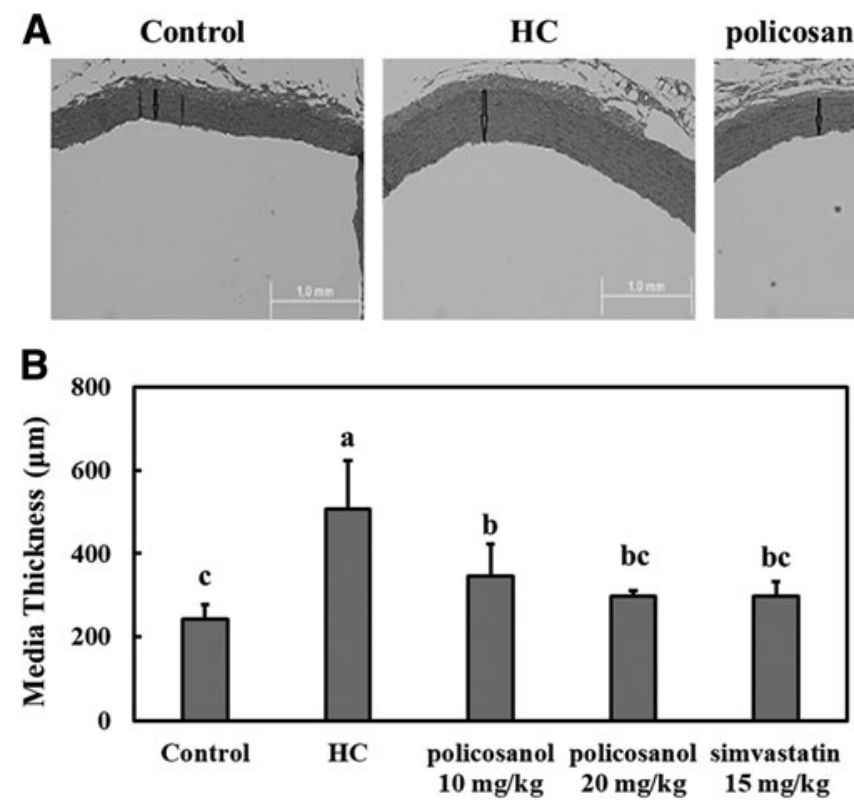

D

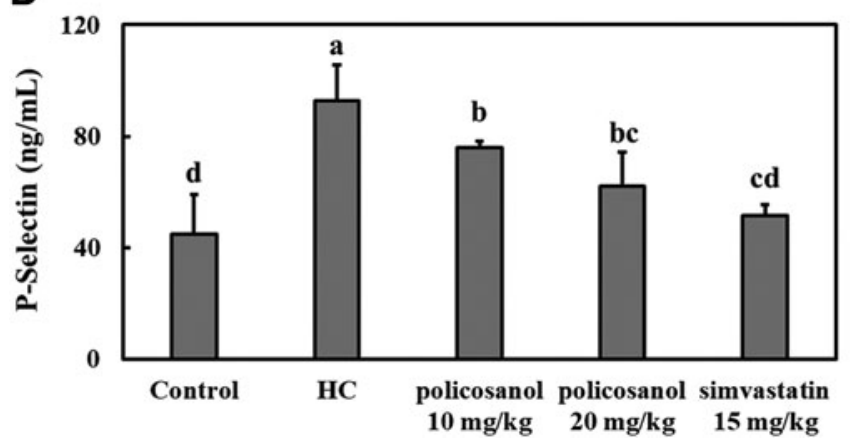

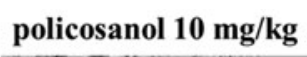

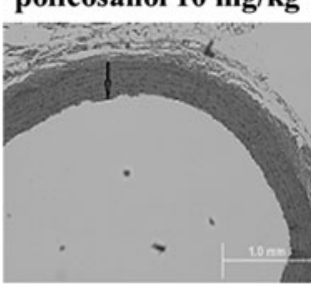

policosanol $20 \mathrm{mg} / \mathrm{kg}$
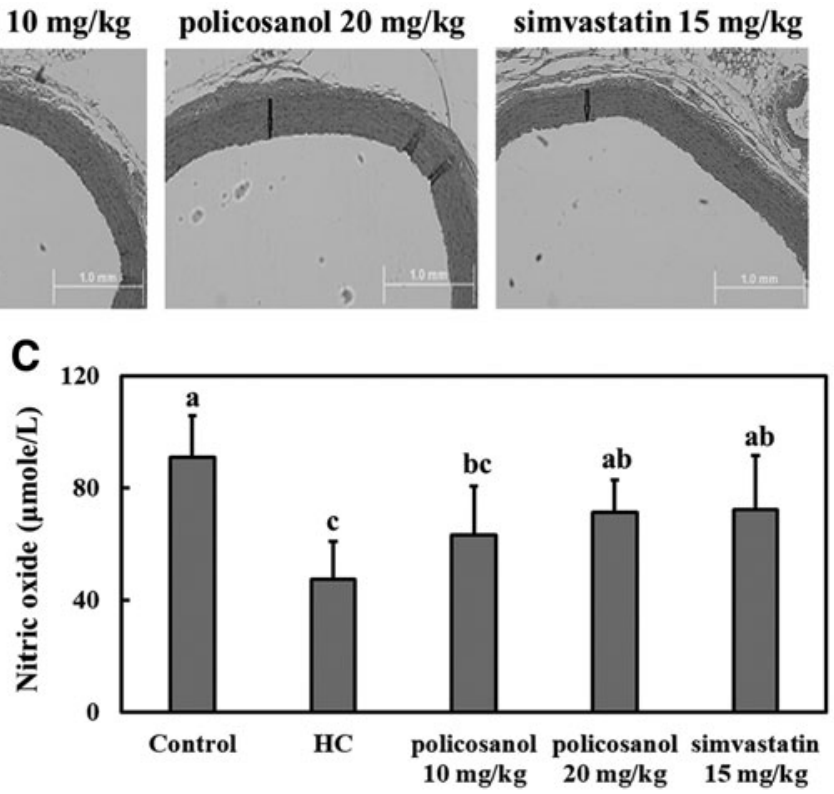

$\mathbf{E}$

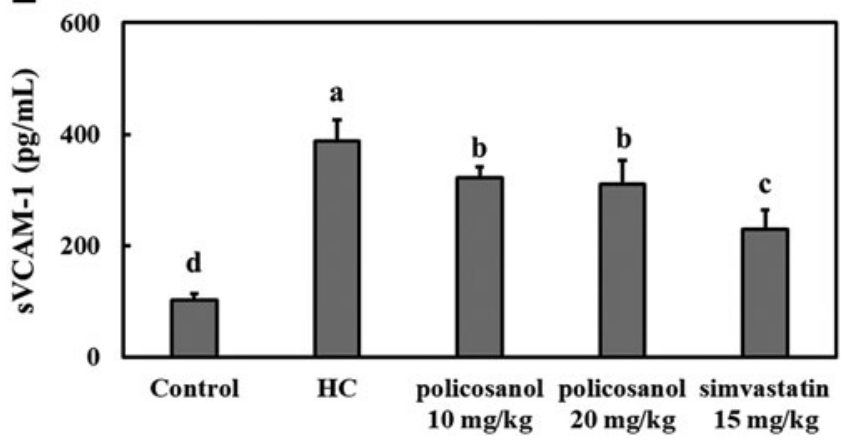

FIG. 7. Effects of policosanol supplementation on aortic wall thickness (A, B), nitric oxide (C), P-selectin (D), and sVCAM-1 levels (E) in hypercholesterolemic rats. Control, normal AIN93M diet control group; HC, high-fat and high-cholesterol diet control group; policosanol $10 \mathrm{mg} / \mathrm{kg}$, high-fat and high-cholesterol diet with policosanol $10 \mathrm{mg} / \mathrm{kg}$ b.w. group; policosanol $20 \mathrm{mg} / \mathrm{kg}$, high-fat and high-cholesterol diet with policosanol $20 \mathrm{mg} / \mathrm{kg}$ b.w. group; and simvastatin $15 \mathrm{mg} / \mathrm{kg}$, positive control high-fat and high-cholesterol diet with simvastatin $15 \mathrm{mg} / \mathrm{kg} \mathrm{b.w}$. group. Values are presented as means \pm SD. Different letters show a significant difference at $P<.05$, as determined by Duncan's multiple range test.

Thus, it is important to remove cholesterol by blocking reabsorption and promoting excretion of bile acid. ${ }^{22,23} \mathrm{We}$ found that treatment with policosanol at $20 \mathrm{mg} / \mathrm{kg}$ b.w. or simvastatin (positive control; statin class drug) increased the fecal output of cholesterol and bile acid. $\mathrm{Ng}$ et al. ${ }^{24}$ also found that at hamsters given policosanol for 6 weeks increased the excretion of acidic sterols. These findings suggest that policosanol may stimulate hepatic cholesterol catabolism by the conversion of cholesterol into bile acids.

HMG-CoA reductase is a rate-limiting enzyme of cholesterol biosynthesis and a key enzyme for cholesterol homeostasis. ${ }^{5}$ Thus, we used simvastatin, an inhibitor of HMG-CoA reductase, as a positive control and examined HMG-CoA reductase mRNA expression and activity. Interestingly, we found that policosanol supplementation did not affect mRNA expression of HMG-CoA reductase, but it did decrease HMG-CoA reductase activity during high-fat and high-cholesterol-containing diet-induced development of hypercholesterolemia. In addition, policosanol supple- mentation stimulated AMPK phosphorylation, which can effectively inhibit cholesterol levels in both the cell and blood by deactivating HMG-CoA reductase. ${ }^{6}$ Thus, effects of policosanol supplementation were similar to those of simvastatin treatment. Banerjee et al. reported potential policosanol roles, stating that the linking of long chain alcohols to activated fatty acids by policosanol in hepatoma cells caused suppression of cholesterol synthesis by increasing cellular AMP levels, causing the phosphorylation of AMPK and HMG-CoA reductase inhibition. ${ }^{14}$ This HMG-CoA reductase inhibition and cholesterol biosynthesis can trigger LDL receptor expression for uptake of circulating LDL cholesterol into the cells. ${ }^{14}$ The present data also show that policosanol and simvastatin supplementation stimulated the expression of both LDL receptor mRNA and protein, indicating that policosanol suppressed the increase in cholesterol levels in the blood by AMPK-induced HMGCoA reductase deactivation and LDL cholesterol uptake through the LDL receptor. 
ACAT2 is expressed in the liver and small intestine and catalyzes an esterification reaction to convert free cholesterol to cholesterol esters for intracellular storage. In the liver, ACAT2 causes the secretion of cholesteryl esters by binding with the ApoB-containing lipoproteins. ${ }^{25}$ Lee et al. demonstrated that treatment with Barley sprout extract containing policosanol for $24 \mathrm{~h}$ decreased the transcription and protein levels of ACAT2 in HepG2 cells. ${ }^{26}$ However, our findings in rats showed no difference in hepatic ACAT2 protein levels between the $\mathrm{HC}$ and policosanol groups, but a significant decrease in hepatic ApoB protein levels. Thus, although further research is needed, these data suggest that policosanol does not affect ACAT-generated ApoB-containing lipoproteins in the liver, but it stimulates the secretion of ApoB-containing lipoproteins. We also found that policosanol supplementation decreased atherosclerotic wall thickness and factors of endothelial cell activation such as P-selectin and SVCAM-1. ${ }^{27}$ Thus, we suggest that policosanol has a protective effect against atherosclerotic lesions in hypercholesterolemia.

In conclusion, we demonstrated the protective effect of policosanol on a high-fat and high-cholesterol-containing diet-induced hypercholesterolemia in rats. Policosanol supplementation inhibited cholesterol biosynthesis through AMPK activation and HMG-CoA reductase deactivation, accelerated excretion of cholesterol and bile acids, and uptake of LDL cholesterol from the blood by the LDL receptor during hypercholesterolemia development. Taken together, our results provide a strong evidence supporting beneficial effects of policosanol on hypercholesterolemia.

\section{AUTHOR DISCLOSURE STATEMENT}

The authors declare no conflicts of interest.

\section{FUNDING INFORMATION}

No funding was received for this article.

\section{REFERENCES}

1. Katz J, Chaushu G, Sharabi Y: On the association between hypercholesterolemia, cardiovascular disease and severe periodontal disease. J Clin Periodontol 2001;28:865-868.

2. Ten Kate GR, Bos S, Dedic A, et al: Increased aortic valve calcification in familial hypercholesterolemia: Prevalence, extent, and associated risk factors. J Am Coll Cardiol 2015;66:2687-2695.

3. Li T, Chiang JY: Regulation of bile acid and cholesterol metabolism by PPARs. PPAR Res 2009;2009:501739.

4. Nishina PM, Freedland RA: The effects of dietary fiber feeding on cholesterol metabolism in rats. J Nutr 1990;120:800-805.

5. Burg JS, Espenshade PJ: Regulation of HMG-CoA reductase in mammals and yeast. Prog Lipid Res 2011;50:403-410.

6. Singh DK, Banerjee S, Porter TD: Green and black tea extracts inhibit HMG-CoA reductase and activate AMP kinase to decrease cholesterol synthesis in hepatoma cells. J Nutr Biochem 2009;20:816-822.

7. Brown MS, Goldstein JL: The SREBP pathway: Regulation of cholesterol metabolism by proteolysis of a membrane-bound transcription factor. Cell 1997;89:331-340.

8. Thompson PD, Panza G, Zaleski A, Taylor B: Statin-associated side effects. J Am Coll Cardiol 2016;67:2395-2410.
9. Ballard KD, Taylor BA, Thompson PD: Statin-associated muscle injury. Eur J Prev Cardiol 2015;22:1161.

10. Koh JH, Kim JM, Chang UJ, Suh HJ: Hypocholesterolemic effect of hot-water extract from mycelia of Cordyceps sinensis. Biol Pharm Bull 2003;26:84-87.

11. Ahmed I, Lakhani MS, Gillett M, John A, Raza H: Hypotriglyceridemic and hypocholesterolemic effects of anti-diabetic Momordica charantia (karela) fruit extract in streptozotocininduced diabetic rats. Diabetes Res Clin Pract 2001;51:155161.

12. Luo QF, Sun L, Si JY, Chen DH: Hypocholesterolemic effect of stilbenes containing extract-fraction from Cajanus cajan L. on diet-induced hypercholesterolemia in mice. Phytomedicine 2008; 15:932-939.

13. Irmak S, Dunford NT: Policosanol contents and compositions of wheat varieties. J Agric Food Chem 2005;53:5583-5586.

14. Banerjee S, Ghoshal S, Porter TD: Activation of AMP-kinase by policosanol requires peroxisomal metabolism. Lipids 2011;46: 311-321.

15. Varady KA, Wang Y, Jones PJ: Role of policosanols in the prevention and treatment of cardiovascular disease. Nutr Rev 2003;61:376-383.

16. Zheng S, Hoos L, Cook J, et al.: Ezetimibe improves high fat and cholesterol diet-induced non-alcoholic fatty liver disease in mice. Eur J Pharmacol 2008;584:118-124.

17. Brusq JM, Ancellin N, Grondin P, et al: : Inhibition of lipid synthesis through activation of AMP kinase: An additional mechanism for the hypolipidemic effects of berberine. J Lipid Res 2006;47:1281-1288.

18. Stillemark-Billton P, Beck C, Borén J, Olofsson SO: Relation of the size and intracellular sorting of apoB to the formation of VLDL 1 and VLDL 2. J Lipid Res 2005;46:104-114.

19. Capron L: Atherosclerosis is an inflammatory disease. Rev Med Interne 1988;9:359-361.

20. Paik HD, Park JS, Park E: Effects of Bacillus polyfermenticus SCD on lipid and antioxidant metabolisms in rats fed a high-fat and high-cholesterol diet. Biol Pharm Bull 2005;28:1270-1274.

21. Tang LQ, Wei W, Chen LM, Liu S: Effects of berberine on diabetes induced by alloxan and a high-fat/high-cholesterol diet in rats. J Ethnopharmacol 2006;108:109-115.

22. Gallaher CM, Munion J, Hesslink R Jr., Wise J, Gallaher DD: Cholesterol reduction by glucomannan and chitosan is mediated by changes in cholesterol absorption and bile acid and fat excretion in rats. J Nutr 2000;130:2753-2759.

23. Hofmann AF: Bile acids: The good, the bad, and the ugly. News Physiol Sci 1999;14:24-29.

24. Ng CH, Leung KY, Huang Y, Chen ZY: Policosanol has no antioxidant activity in human low-density lipoprotein but increases excretion of bile acids in hamsters. J Agric Food Chem 2005;53:6289-6293.

25. Temel RE, Hou L, Rudel LL, Shelness GS: ACAT2 stimulates cholesteryl ester secretion in apoB-containing lipoproteins. J Lipid Res 2007;48:1618-1627.

26. Lee JH, Lee SY, Kim B, et al.: Barley sprout extract containing policosanols and polyphenols regulate AMPK, SREBP2 and ACAT2 activity and cholesterol and glucose metabolism in vitro and in vivo. Food Res Int 2015;72:174-183.

27. Koyama H, Maeno T, Fukumoto S, et al.: Platelet P-selectin expression is associated with atherosclerotic wall thickness in carotid artery in humans. Circulation 2003;108:524-529. 